\title{
High Efficient Removal of Tetracycline from Solution by the Nanoscale Zerovalent Iron
}

\author{
Yuncong Fu, Qingru Zeng, Liang Peng ${ }^{a, *}$, Huijuan Song, Jihai Shao, Jidong \\ $\mathrm{Gu}$
}

Department of Environmental Science \& Engineering, Hunan Agricultural University, Changsha 410128, China

apengliang2004@126.com

Keywords: Iron, tetracycline, flocculation, complex.

\begin{abstract}
The degradation and flocculation of tetracycline (TC) with nanoscale zerovalent iron (NZVI) modified by starch were investigated using batch experiments as a function of reactant concentration, $\mathrm{pH}$, and ion strength. The $500 \mathrm{mg} / \mathrm{L}$ TC was processed with $0.20 \mathrm{mg} / \mathrm{L} \mathrm{NZVI}$, the adsorption and degradation effect was only $30.0 \%$ and flocculation effect was $69.0 \%$, the total removal efficiency was as high as $99.2 \%$. At processed with NZVI, the flocculation kinetics of TC was strongly dependent on $\mathrm{pH}$ and ion strength. Neutral environment and high ion strength can improve the sedimentation rate.
\end{abstract}

\section{Introduction}

Antibiotics discharged from wastewater treatment plants (WWTPs) to the environment have received increasing attentions due to propagation of antibiotic resistance in microorganisms [1-2]. Tetracycline (TC) is one of the most widely used antibiotics worldwide, and is difficult to be metabolized in animals. Consequently, large fraction of TC has been end up in the wastewater system. Due to its inability to be treated in WWTPs, TC has been widely detected in soils, surface waters, ground water, coastal environment, and even drinking water due to discharge into the environment [3].

The removal efficiencies of TC are very low in WWTPs with active sludge treatment processes [4-5] because TC is non-biodegrable and also lethal to most microorganisms. Therefore, adsorption [6], electron pulse radiolysis [7] and photo catalysis [8] have been adopted to treat TC before WWTPs. Recently the use of zerovalent iron (ZVI) has received wide attention for the treatment of toxic compounds since it is a strong reducing agent, inexpensive, and nontoxic. There have been several attempts to eliminate a variety of pollutants, including chlorinated organic compounds, nitro aromatic compounds, pesticides, dyes, and heavy metals using ZVI with high efficiency. However, a little attention has been given to the interaction of antibiotics with ZVI [9-11]. In which, the ZVI degradation and adsorption effect for TC has been reported by Chen et al. (2011) [12] and Ozge Hanay et al. (2014) [13]. The degradation products mainly include the 4-epi-tetracycline and loss of amine and water as TC-like matter. The ZVI can transform as iron (hydroxyl) oxides quickly, and then adsorb the degradation products and TC in $15 \mathrm{~min}-4 \mathrm{~h}$. The TC is the efficient chelating agent for metal ion with high valet. Thus, the iron ion dissolved in solution can be interacted with TC as complex. This Fe chelating with TC cannot decrease the antibiotic effect of TC [14], and should be removal from the wastewater before WWTPs. What is the fate of the Fe chelating with TC? In our experiment, the flocculation phenomenon of Fe-chelating with TC and degradation products was found. Factually, this flocculation is very more efficient than the degradation and adsorption on removal of the TC form solution.

In our experiment, the main aim was to examine long-term process of TC removal by NZVI in different condition such as $\mathrm{pH}$, TC concentration, and ion strength. 


\section{Experimental}

Synthesis procedures. The starch-NZVI particles were synthesized by using the well-known liquid-phase reduction method. A 500-mL flask attached to a vacuum pump, 0.04 mol $\mathrm{FeSO}_{4} \cdot 7 \mathrm{H}_{2} \mathrm{O}$ was dissolved into $300 \mathrm{~mL}$ ethanol solution (70\% volume), then starch powder (the weight ratio of starch to NZVI is 0.2-0.5) was added with vigorous agitation. After sparging with $\mathrm{N}_{2}$ for 10 min, 100 $\mathrm{mL} 0.02 \mathrm{M}$ borohydride solution was slowly added into the above mixture and stirred for $20 \mathrm{~min}$ at $25^{\circ} \mathrm{C}$. $\mathrm{Fe}^{2+}$ was reduced by $\mathrm{BH}_{4}{ }^{-}$to form black NZVI particles immediately. NZVI particles were collected by vacuum filtration and washed several times with deionized (DI) water and ethanol. The resulting black solids were vacuum-dried for $15 \mathrm{~h}$ at $40^{\circ} \mathrm{C}$, broken up by a spatula and stored in a $\mathrm{N}_{2}$-purged desiccator.

Batch experiments. In the batch experiments, TC solutions (TC $500 \mathrm{mg} / \mathrm{L}$; ionic strength $0.01 \mathrm{M}$ $\mathrm{NaCl}$ ) were prepared fresh daily for each batch test. To start the experiments, $50 \mathrm{~mL}$ of the prepared TC solution was purged with nitrogen for $10 \mathrm{~min}$ in a $100 \mathrm{~mL}$ plastic bottle. Then the solution was mixed with $0.010 \mathrm{~g}$ freshly prepared starch-NZVI. The plastic bottle sealed with cover was continuously shaked (150 rpm) for $2 \mathrm{~h}$ at $25^{\circ} \mathrm{C}$, and placed it in 7 days after filtered. At selected time intervals, pairs of centrifuge tubes were centrifuged ( $8700 \times \mathrm{g}$ for $5 \mathrm{~min}$ ) and then collected with glass syringes and filtered through a $0.45 \square$ m membrane filter for analysis. One or two drops of $12 \mathrm{~mol} / \mathrm{L}$ $\mathrm{HCl}$ were added into the filtrate to adjust solution $\mathrm{pH}$ to $1-2$ in order to dissociate the complex of TC and Fe in solution.

Each experiment, including blanks, was run in duplicate. The $\mathrm{pH}$ of the samples was measured by a $\mathrm{pH}$ electrode. Other experimental conditions and measurements except the $\mathrm{pH}$ reaction were set at the condition of dosage of starch-NZVI, $0.010 \mathrm{~g}$; temperature, $25^{\circ} \mathrm{C} ; \mathrm{pH}, 6.0$. Ionic strength $0.01 \mathrm{M}$ $\mathrm{NaCl}$. Ionic strength experiment used solutions of $500 \mathrm{mg} / \mathrm{L} \mathrm{TC}$ add $\mathrm{NaCl}$ to desired concentration, $\mathrm{pH}$ 6.0.

TC concentration analysis. The concentration of TC in the solution was analyzed using High

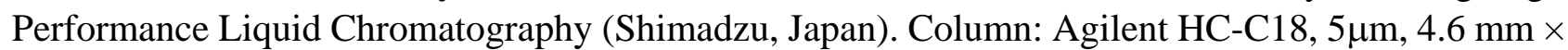
$250 \mathrm{~mm}$; The mobile phase was a mixture of $0.01 \mathrm{M}$ oxalic acid-acetonitrile-methanol (45:35:20, v/v); flow rate: $1.0 \mathrm{~mL} / \mathrm{min}$; detector: $\mathrm{UV}$ at $360 \mathrm{~nm}$ and sample size: $20 \mu \mathrm{L}$ [12].

\section{Results and discussion}

Factors affecting the removal of TC. Removal Kinetics. The removal properties of TC to starch-NZVI were evaluated by putting $0.010 \mathrm{~g}$ starch-NZVI into $50 \mathrm{~mL}$ of $500 \mathrm{ppm} \mathrm{TC} \mathrm{(pH} \mathrm{at} \mathrm{2,} \mathrm{4,} \mathrm{6,}$ 7,8 and 10) at room temperature. The removal process were composed of two stage, the first one is the quick adsorption at 1-4 h, and then the seconded one is slow sedimentation at 4-30 d. The quick adsorption process have been investigated in detail by the Chen (2011) [12] and Ozge Hanay (2014)[13]. The TC was degraded by the NZVI, as anhydrotetracycline (ATC) and 4-epianhydrotetracycline (ETAC), and then adsorbed with the $\mathrm{Fe}_{3} \mathrm{O}_{4}$ and $\mathrm{FeOOH}$. However, the TC removal capacity of quick absorption is $30-1800 \mathrm{mg} / \mathrm{g}$ [12]. The slow sedimentation process can remove high-efficiently TC from waterbody. In our experiment, the total adsorption is about 2480.7 $\mathrm{mg} / \mathrm{g}$ (quick adsorption capacity is only $750 \mathrm{mg} / \mathrm{g}$ ), when the $500 \mathrm{ppm}$ TC was processed with $0.20 \mathrm{~g} / \mathrm{L}$ NZVI at pH 6. The $\mathrm{pH}$ has an important effect on the TC removal efficiency and kinetics.

The removal efficiency of TC was shown as a function of initial $\mathrm{pH}(2.0,4.0,6.0,7.0,8.0$ and 10.0) within $4 \mathrm{~h}$ in Fig.3. From $\mathrm{pH} 2.0$ to $\mathrm{pH} 7.0$, the adsorption capacity of TC was increase from 314.44 $\mathrm{mg} / \mathrm{g}$ to $743.47 \mathrm{mg} / \mathrm{g}$, but at $\mathrm{pH} 8.0$ and 10 it decreased to $699.11 \mathrm{mg} / \mathrm{g}$ and $649.11 \mathrm{mg} / \mathrm{g}$, respectively. These results indicated that the removal of TC by starch-NZVI was effective in both acidic and neutral $\mathrm{pH}$ by the quick adsorption process. These results are corresponding to the report of Chen (2011). All TC species in solution have positive, zwitterion and negative charges as $\mathrm{H}_{3} \mathrm{~L}^{+}, \mathrm{H}_{2} \mathrm{~L}^{0}, \mathrm{HL}^{-}$ and $\mathrm{L}^{2-}$ (Fig.1). In this $\mathrm{pH}$ range $(3.3<\mathrm{pH}<7.7), \mathrm{H}_{2} \mathrm{~L}^{0}$ is the predominant TC species while the NZVI 
surfaces are positive causing $\mathrm{H}_{2} \mathrm{~L}^{0}$ species of TC was adsorbed onto the positive charged NZVI surface. As $\mathrm{pH}$ is above $7.7\left(\mathrm{pKa}_{2}\right), \mathrm{HL}^{-}$and $\mathrm{L}^{2-}$ are the predominant TC species while the NZVI surfaces are also negative causing electrostatic repulsion. Consequently, the removal efficiency of TC at $\mathrm{pH} 8.0$ and 10.0 decreased. However, the removal efficiency in strong acidic environment is very lower than that of neutral and basic environment. This result is not corresponding to that of the Chen (2011) [12], but as the report of Ozge Hanay (2014)[13]. It is ascribed to that the strong acid can reactive with the iron as $\mathrm{Fe}^{3+}$ not as the iron (hydroxyl) oxide. The $\mathrm{Fe}^{3+}$ cannot adsorb the TC from the acid environment.

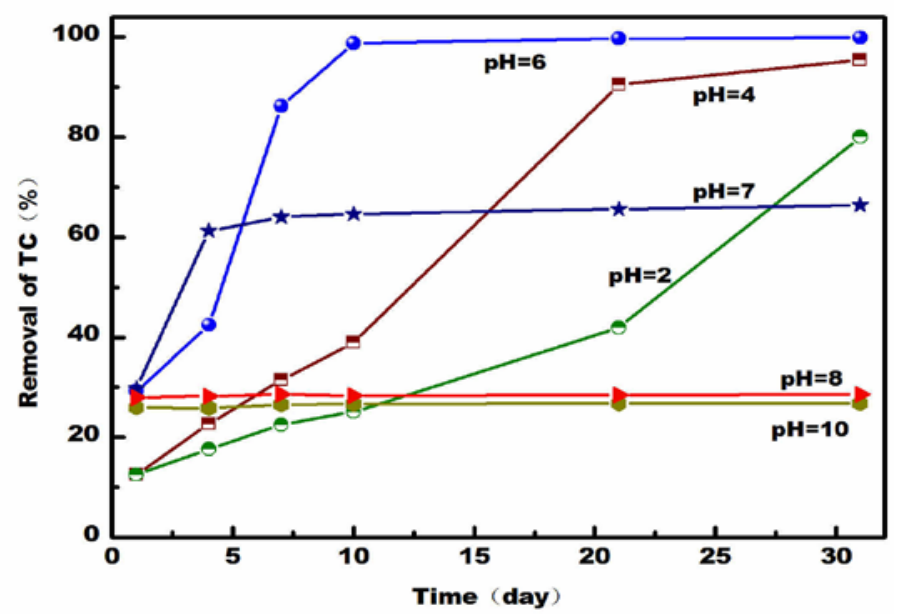

Fig. 1 The influence of $\mathrm{pH}$ on the removal kinetics of TC by starch-NZVI

The brown deposit in acid and neutral environment has been found after more than $24 \mathrm{~h}$. The deposit is the Fe-TC complex with formation constant of 13.4 [15]. The sedimentation rate in different $\mathrm{pH}$ is in this sequence: $\mathrm{pH} 7>\mathrm{pH} 6>\mathrm{pH} 4>\mathrm{pH} 2>>\mathrm{pH} 8 \sim \mathrm{pH} 10$. Not any deposit is found in the basic environment, such as pH8 and 10, even after 30 day. The total TC removal capacity by NZVI at pH7, pH6, pH4, pH2, pH8 and pH10 is 65.9\%, 99.2\%, 92.0\%, 80.1\%, 31.9\% and 30.9\%, respectively. The pH6 is the appropriated sedimentation $\mathrm{pH}$, due to it can deposit the Fe-TC in 7 day, and the total removal capacity of TC is the largest than other $\mathrm{pH}$. This sedimentation rate is corresponding to the isoelectric point of the Fe-TC. At the acidic (basic) environment, the Fe-TC is with positive (negative) charge and cannot aggregate to precipitate.

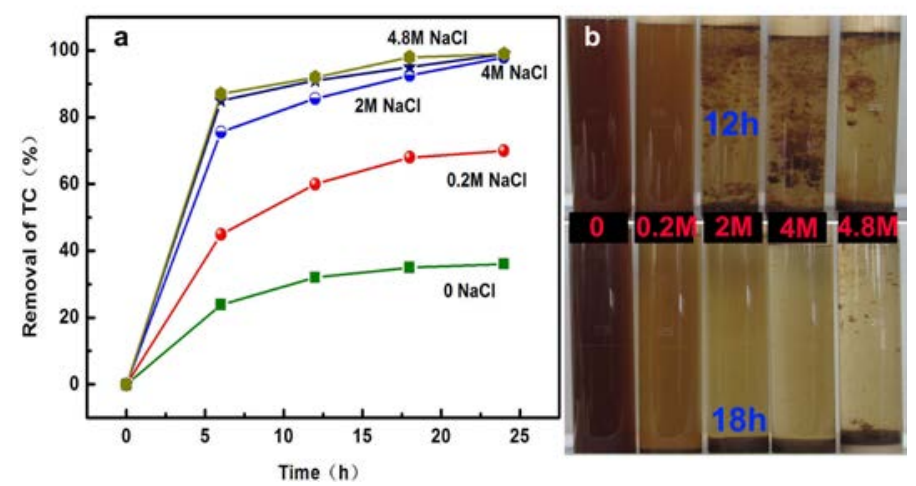

Fig.2 the influence of ion strength on the sedimentation rate of Fe-TC complex. a)the effect of 0, 0.2 $\mathrm{M}, 2.0 \mathrm{M}, 4.0 \mathrm{M}$ and $4.8 \mathrm{M} \mathrm{NaCl}$ solution on the removal of TC by NZVI, b) the sedimentation pictures of the Fe-TC complex in different $\mathrm{NaCl}$ concentration in $12 \mathrm{~h}$ and $18 \mathrm{~h}$.

\section{The ion strength effect on the sedimentation rate.}

The Fe-TC complex should be as colloid in the solution, and then aggregate to deposit after $\sim 7$ day. The sedimentation rate is too slow in practiced application. Therefore, the improvement of the sedimentation rate was investigated through the increase of the ion strength of the solution. The 50 $\mathrm{mL}$ solution with $500 \mathrm{mg} / \mathrm{L}$ TC was processed with $0.010 \mathrm{~g} \mathrm{NZVI}$, when the solution was of $0,0.2 \mathrm{M}$, 2.0M, 4.0M, 4.8M (saturated concentration) $\mathrm{NaCl}$, respectively. The results showed that the ion 
strength can improve effectively the sedimentation rate of Fe-TC complex. The sedimentation rate is increase as increase the ion strength as shown in Fig.5. When the $\mathrm{NaCl}$ concentration was higher than 2.0 M, 99\% Fe-TC complex colloid could be deposited after 24h. It is attributed to that the single particles or the flocs may collide with the other particles or flocs and aggregate during settling, in high salinity situation.

\section{Conclusion}

The present study demonstrated that the starch-NZVI can be used as an effective and low-cost material for the TC removal in wastewater. The performance of batch experiments under various conditions indicated that starch-NZVI had superior removal ability toward TC over the range of $50.0-1000.0 \mathrm{mg} / \mathrm{L}$. There were two stages in the reaction process, the first stage was TC degradation and adsorption process, and the second stage was TC flocculation process. $\mathrm{pH}$ is a significant factor affecting the removal efficiency of TC by starch-NZVI. The removal of TC is more effective in neutral $\mathrm{pH}$ than other environment. The high concentration ion strength greatly improves the sedimentation rate.

\section{Acknowledgments}

This project was supported by the Postdoctoral Science Foundation of Central South University. For the financial support we are grateful to the National Natural Science Foundation of China (No.41401260, 21007014) and Natural Science Foundation of Hunan Province (13JJ04068).

\section{References}

[1] H. Storteboom, M. Arabi, et al: Environ. Sci. Technol., Vol. 44(2010) No. 19, p. 7397-7404.

[2] H. Schmitt, K. Stoob, et al: Microb. Ecol., Vol. 51(2006) No. 3, p. 267-276.

[3] Y. Gao, Y. Li, L. Zhang, et al: J. Colloid Interface Sci., vol.368(2012) No. 1, p. 540-546.

[4] X.S. Miao, F. Bishay, M. Chen, et al: Environ. Sci. Technol, Vol. 38(2004) No. 13, p. 3533-3541.

[5] R. Alexy, T. Kumpel, K. Kummerer: Chemosphere, vol. 57(2004) No. 6, p. 505-512.

[6] L. Peng, Y.Q. Ren, J.D. Gu, et al: Environ. Sci. Pollut. Res, Vol. 21(2014) No. 12, p.7631-7640.

[7] J. Jeong, W. Song, W.J. Cooper, et al: Chemosphere, vol. 78(2010) No. 55, p. 533-540.

[8] J. Bai, Y.B. Liu, J.H. Li, et al: Appl. Catal. B: Environ., Vol. 98(2010) No. 3-4, p. 154-160.

[9] A. Ghauch, H.A. Assi, S. Bdeir: J Hazard Mater, vol. 182(2010) No. 1-3, p. 64-74.

[10]Z. Fang, J. Chen, X. Qiu, et al: Desalination, vol. 268(2011) No. 1-3, p. 60-67.

[11]I.R. Bautitz, A.C. Velosa, R.F.P. Nogueira: Chemosphere, vol. 88(2012) No. 6, p. 688-692.

[12]H. Chen, H.J. Luo, Y.C. Lan, et al: J. Hazard. Mater, Vol. 192 (2011) No. 1, p. 44-53.

[13]H. Ozge, Y. Burçin, et al: Environ Sci Pollut Res, Vol. 21 (2014) No. 5, p.3774-3782.

[14]D. Grenier, M.P. Huot, D. Mayrand: Antimicrob. Agents Chemother, Vol. 44(2000) No. 3, p.763-767.

[15]J.M. Wessels, W.E. Ford, et al: J. Phys. Chem. B, vol. 102 (1998) No. 46, p. 9323-9331. 